UDC 57.089

LBC 28.74

\title{
MULTIDIMENSIONAL BIOLOGY AS THE BASIS OF PERSONALIZED MEDICINE AND MEDICINE OF THE XXI CENTURY
}

\author{
Maria V. Grunina \\ Volgograd State University, Volgograd, Russian Federation \\ Mikhail P. Liabin \\ Volgograd State University, Volgograd, Russian Federation
}

\begin{abstract}
The review describes key branches of medicine of the XXI century. The authors describe the main direction to provide progress in current medicine: the transition from classical clinical diagnosis to personalized one (1); testing human predisposition to various diseases at the genomic level (2); and selection of individual drugs and treatment regimens, its monitoring, through the use of biomarkers (3). The mechanisms of action of various directions of multidimensional biology in specialized medicine are considered.
\end{abstract}

Key words: genomics, transcriptomics, proteomics, metabolomics, medicine, personalized medicine.

УДК 57.089

ББК 28.74

\section{МНОГОМЕРНАЯ БИОЛОГИЯ КАК ОСНОВА ПЕРСОНАЛИЗИРОВАННОЙ МЕДИЦИНЫ И МЕДИЦИНЫ ХХІ ВЕКА}

\author{
Мария Викторовна Грунина \\ Волгоградский государственный университет, г. Волгоград, Российская Федерация \\ Михаил Павлович Лябин \\ Волгоградский государственный университет, г. Волгоград, Российская Федерация
}

\begin{abstract}
Аннотация. Описаны ключевые отрасли медицины XXI века. Авторы рассмотрели три основных направления в развитии современной медицины: переход от классической клинической диагностики к персонализированной; тестирование человека на предрасположенность к различным заболеваниям на геномном уровне; подбор индивидуальных лекарственных препаратов и схемы лечения, его мониторинг, путем использования биомаркеров. Рассмотрены механизмы действия различных направлений многомерной биологии в специализированной медицине.
\end{abstract}

Ключевые слова: геномика, транскриптомика, протеомика, метаболомика, медицина, персонализированная медицина.

В современное время всю большую актуальность приобретает распространение таких заболеваний как сахарный диабет, онкологические заболевания, метаболический синдром, атеросклероз, ишемические болезни сердца, ожирение и пр. Персонализированная медицина, как интегральная медицина, включающая в себя тестирование человека () на предрасположенность к различным забо- леваниям на основе геномных данных, разработку персонализированных средств лечения, является основным инструментом в борьбе с перечисленными выше заболеваниями цивилизации [7].

Целью персонализированной медицины является подбор лекарственного препарата для конкретного пациента, даже если при этом необходима разработка персональной схемы 
лечения с учетом его индивидуальных данных, что обусловлено тем, что классические схема лечения различных заболеваний все чаще оказываются неэффективными ввиду проявлений побочных эффектов [7; 10].

Основными подходами медицины XXI в. являются $[5 ; 12 ; 14]$ :

- переход от классической клинической диагностики к персонализированной;

- тестирование человека на предрасположенность к различным заболеваниям на геномном уровне;

- подбор индивидуальных лекарственных препаратов и схемы лечения, его мониторинг, путем использования биомаркеров.

OMICS (gemomics, transcriptomics, proteomics, metabolomics) - основа персонализированной медицины [2].

Геномика представляет собой идентификацию всех генов человека и нарушений в них, приводящих либо к наследственным заболеваниям, либо к предрасположенности к ним. Расшифровка генома человека, которая позволила получать информацию об особенностях конкретного человека, а, значит, и информацию о характере возникновению и течения заболевания, реакцию организма на различные лекарственные препараты и методы лечения, сыграла решающую роль в создании персонализированной медицины [2; 9].

Ранее исследования отдельных генов и локусов также создали существенные предпосылки для персонализации. Для оценки значимости обнаруживаемых индивидуальных единичных нуклеотидных полиморфизмов (SNP) в анализируемых генах проводят исследования сравнения частоты их встречаемости между здоровыми лицами и группами больных. Предсказательную информативность обнаруживаемых SNP оценивают по коэффициенту риска (odds ratio, OR), указывающему, во сколько раз чаще данный маркер встречается у больных, чем в популяции в целом. Установлено более 2400 SNP, статистически достоверно ассоциированных с заболеваниями с высокими OR [8; 13].

Наибольшее число работ по определению персонализированных геномных характеристик связано с онкологией. Отмечается, что геномный «молекулярный профиль» биоптата опухоли является уникальной характеристикой опухоли конкретного больного. Специфичные для онкологических заболеваний мутации подробно охарактеризованы в геномном атласе рака (Cancer Genome Atlas), создававшемся в течение 10 лет и потребовавшем более 1 млрд долларов затрат [11]. Одним из первых применений геномики в онкологии была работа по анализу SNP для уточнения классификации отдельных видов лейкозов у больных, способствующая выбору индивидуальной терапии для больных с внешне близкими клиническими признаками болезни. В настоящее время рядом компаний коммерциализованы тесты для выявления предрасположенности к ряду заболеваний, в особенности онкологических $[2 ; 11]$.

Развитие геномики позволяет, однако, не только проводить молекулярно-генетическую диагностику, но и, как следующий этап, определять интенсивность синтеза РНК и белков, имеющих отношение к возникновению и развитию заболеваний [6].

Транскриптомика представляет собой идентификацию всех матричных РНК, кодирующих белки, определение количества каждой индивидуальной мРНК, определение закономерностей экспрессии всех генов, кодирующих белки [5].

Определение интенсивности синтеза РНК и белков, имеющих отношение к возникновению и развитию заболеваний, происходит с помощью транскрипционных профилей, характеризующих экспрессию всех генов, активных в данном образце. Технологии, применяемые для решения этих задач, основаны на так называемых «ДНК микрочипах» (DNA microarray). Генный чип представляет собой твердую подложку, на которую в определенном порядке нанесены в виде точек индивидуальные гены (их ДНК). Чтобы определить, транскрибируется ли данный ген, на чип помещают (с определенными координатами) лишь его часть - олигонуклеотид. Этот олигонуклеотид соответствует экспрессируемой части гена (экзону). Затем из образца (например, опухоль) выделяется вся (суммарная) РНК. На основе всех молекул РНК данного образца получают их ДНК-копии - кДНК (обратная транскрипция), которые флуоресцентно метят и потом проводят гибридизацию с иммобилизованными на микрочипе олигонук- 


\section{МАТЕРИАЛЫ КОНФЕРЕНЦИИ}

леотидами [14]. Если в данных условиях какие-то точки с конкретными генами не гибридизуются - это значит, что данный ген не транскрибируется. Если же данная точка микрочипа «светится», значит олигонуклеотиды на этой площадке прогибридизовались с флуоресцентно меченой кДНК, ген транскрибируется [8].

Чтобы определить, является ли полученный результат ошибкой или нет, проводится сравнение двух объектов. Для этого берут образец А (патология), из него получают суммарную РНК и после обратной транскрипции всех ее молекул флуоресцентно метят определенным цветом (красным) все молекулы кДНК. То же проводят и с образцом В (норма), но метят молекулы кДНК другим цветом (зеленым). Затем проводят гибридизацию ДНК-микрочипа со смесью этих двух препаратов кДНК (конкурентная гибридизация преимущественно образуют гибриды те молекулы, которых больше). Если сигнал в данной точке на чипе будет красным, значит в клетках А (патология) транскрипция данного гена сильней, чем в клетках В (норма). Если сигнал зеленый, то транскрипция сильнее в клетках В (норма). Если красного и зеленого поровну, то получится желтый цвет. Таким образом, можно сравнивать уровень транскрипции данного гена в разных тканях и органах, в биологических жидкостях при норме и патологии, до терапии и в ее процессе, до хирургической операции и после. Довольно часто термины «геномика», «транскриптомика» и «протеомика» употребляются в одном и том же значении - для обозначения анализа экспрессии всех генов данного образца - как на уровне синтеза мРНК, так и на уровне синтеза белков.

Транскриптом - набор всех РНК, находящихся в данном образце. Анализ транскриптома, определение качественного и количественного профиля всех синтезированных РНК, отражает синтез кодируемых ими белков, а также синтез рибосомальных, транспортных и других РНК. Сравнение транскриптомов нормальных и патологических образцов, позволяет идентифицировать новые маркеры, прослеживать изменение их уровней во времени, судить о динамике патологии, об эффективности проводимого лечения и прогнозиро- вать его результат [6; 8]. Предполагается, что каждая болезнь, характеризуется своим, так сказать, «штрих-кодом» - уникальным паттерном уровней транскрипции набора генов, характерного именно для данной болезни. Анализ транскриптом осуществляют с помощью компьютерных методов распознавания образов.

Протеомика представляет собой идентификацию и количественное определение всех индивидуальных белков, которые содержатся в биологическом материале (сыворотка крови, спинномозговая жидкость, моча, биопсия) и мониторинг изменения их концентраций. Протеом - совокупность всех белков, содержащихся в данном образце. Полный анализ протеома клеток, тканей, органов и биологических жидкостей проводится с помощью двумерного электрофореза с высоким разрешением и с последующей идентификацией индивидуальных белков за счет масс-спектрометрии. Это позволяет проанализировать до 10000 индивидуальных белков в одном образце и зафиксировать изменения их концентраций. Типичная последовательность операций при протеомике такова:

- отбор образца (клетки, ткань, биологическая жидкость);

- приготовление образца (лизис клеток, экстракция белков);

- изоэлектрофокусировка, электрофорез в 1-ом направлении;

- электрофорез во втором направлении (полиакриламидный гель, додецилсульфат натрия);

- проявление белковых пятен на геле;

- анализ двумерной электрофореграммы (количество пятен, их расположение);

- выделение участков геля, содержащих индивидуальные белковые пятна;

- расщепление индивидуальных белков трипсином прямо в геле;

- масс-спектрометрический анализ: масс-фингерпринтинг пептидов и/или определение аминокислотных последовательностей фрагментов индивидуальных белков;

- идентификация каждого белка и измерение его концентрации, документирование, обработка результатов [7].

Значительному прогрессу в области протеомики способствовали успехи масс-спектро- 
метрического анализа пептидов. Масс-спектрометрия включает в себя четыре основных компонента. Во-первых, в ионном источнике масс-спектрометра из образца получают ионизированные пептиды или белки. Во-вторых, разделение ионов пептидов и белков происходит в анализаторе масс на основе их величины отношения массы к заряду $(\mathrm{m} / \mathrm{z})$. В-третьих, детектор ионов (время пролетного масс-спектрометра), регистрирует отдельные ионы, с указанием значения $\mathrm{m} / \mathrm{z}$ иона, количества ионов, и времени пролета ионов от источника ионов до детектора ионов. И, наконец, интерпретация полученных данных с помощью биоинформатики, анализ баз данных, в итоге, получение дифференциального профиля белков $[5 ; 6]$. $\mathrm{C}$ помощью этой технологии уже открыты новые белковые маркеры и получены впечатляющие результаты в области кардиоваскулярной протеомики и онкопротеомики.

Протеомика тромбоцитов - быстро развивающееся направление. Уже обнаружены ранее неизвестные белки тромбоцитов, быстро идет расшифровка механизмов, приводящих к нарушениям коагуляции. В ранних исследованиях протеомов тромбоцитов было обнаружено, что при активации они секретируют 82 белка. Примерно 35 \% белков, секретирируемых тромбоцитами, синтезируются и другими клетками. Только 28 \% белков, секретирируемых тромбоцитами, обнаруживаются в местах атеросклеротических повреждений. Эти работы привели к идентификации новых мишеней для новых лекарственных препаратов, таких как секретогранин III, циклофилин А, калуменин, а также пролили свет на возможные механизмы адгезии тромбоцитов, способствующие развитию атеросклероза [4].

Метаболомика представляет собой идентификацию и количественное определение всех метаболитов, синтезируемых (или находящихся) в данных клетках, тканях, органах и в биологических жидкостях [3]. Основное направление работ - выявление метаболических изменений, характерных для инициации патологий и ее динамики, для закономерностей ответа метаболизма на терапию. Основные патологии, находящиеся в фокусе метаболомики - метаболический синдром, сахарный диабет, сердечно-сосудистые заболе- вания, патология печени. Метаболомика основана на применении спектроскопии протонного ядерного магнитного резонанса в сочетании с компьютерным анализом распознавания образов. Распознавание образов мультиплетной структуры спектров ЯМР - это новый инструмент изучения структуры и свойств органических соединений. Для лабораторной диагностики определяющее значение имеют спектры протонного ядерного магнитного резонанса сыворотки, спинномозговой жидкости и мочи [3; 5]. Метаболомика уже показала высокую эффективность при обнаружении врожденных и наследственных нарушений метаболизма, нарушений метаболизма, вызванных эндогенными и экзогенными факторами, при трансплантациях (до и после), при изучении токсичности лекарственных препаратов (токсикогеномика), реакций организма на лекарственные препараты (фармакогеномика), при определении индивидуальных особенностей реакции организма на различные пищевые продукты.

Клиническая липидомика - важнейшее направление метаболомики. Нарушения липидного обмена связаны с такими заболеваниями, как атеросклероз, сахарный диабет, ожирение, болезнь Альцгеймера. Липидом липидный профиль грубого липидного экстракта из образца - это масс спектр, характеризующий липидный состав и концентрации всех индивидуальных липидов образца. Подход основан на комбинации жидкостной хроматографии и масс-спектрометрического анализа [6]. Прогресс в липидомике достигнут благодаря разработке новых масс-спектрометрических подходов, в частности, методов «мягкой ионизации», таких как ионизация электрораспылением и матрично-активированная лазерная десорбция / ионизация. В частности, успехи применения метода масс-спектрометрии с ионизацией электрораспылением способствовали развитию «струйной» липидомики (shotgun lipidomics) и практическому применению разделения компонентов внутри источника ионов в качестве стратегии применения двумерной масс-спектрометрии для изучения состава липидов биологических образцов.

Липидомика подразделяется на:

- липидомику клеточной архитектуры и мембран (architecture / membrane lipidomics); 
- липидомику медиаторов (mediator lipidomics).

С помощью липидомики строятся метаболические сети, в которых участвуют (практически) все липиды и медиаторы, являющиеся производными липидов. С помощью этого подхода уже установлено детальное строение мембран многих типов клеток, установлены механизмы активации провоспалительных цитокинов, происходящие за счет медиаторов, связанных с липидами.

Нарушения метаболизма липидов связано с серьезными неврологическими патологиями, включающими биполярные расстройства и шизофрению, а также с нейродегенеративными заболеваниями, такими как болезнь Альцгеймера, болезнь Паркинсона, болезнь Неймана - Пика. Особенно большое значение имеет нейролипидомика спинномозговой жидкости.

В настоящее время персонализированная медицина стоит на пороге значительного расширения возможностей. Геномные и постгеномные технологии должны войти в повседневную практику в самое ближайшее время за счет действия специально ориентированных на это программ. Переоценить значение многомерной биологии для персонализированной медицины невозможно. Использование подходов многомерной биологии уже привело к выявлению новых механизмов возникновения и развития различных патологий, но исследования продолжаются.

\section{СПИСОК ЛИТЕРАТУРЫ}

1. Aronson, S. J. Building the foundation for genomics in precision medicine/ S. J. Aronson, H. L. Rehm // Nature. - 2015. - Iss. 526 (7573). P. 336-342.

2. Chen, R. Promise of personalized omics to precision medicine / R. Chen, M. Snyder // Wiley Interdiscip. Rev. Syst. Biol. Med. - 2013. - Vol. 5, № 1.P. 73-82.
3. Devaskar, S. U. Metabolic programming in the pathogenesis of insulin resistance / S. U. Devaskar, M. Thamotharan // Rev. Endocr. Metab. Disord. - 2007. Vol. 8, № 2. - P. 105-113.

4. Ginsburg, G. S. Comparative effectiveness research, genomics-enabled personalized medicine, and rapid learning health care: a common bond / G. S. Ginsburg, N. M. Kuderer // J. Clin. Oncol. 2012. - Vol. 30, № 34. - P. 4233-4242.

5. Hoggatt, J. Personalized medicine trends in molecular diagnostics: exponential growth expected in the next ten years / J. Hoggatt // Mol. Diagn. Ther. 2011. - Vol. 15, № 1. - P. 53-55.

6. Kaiser, J. The Genome Pproject: what will it do as a teenager? / J. Kaiser // Science. - 2011. Iss. 331 (6018). - e660.

7. Metabolomics enables precision medicine: "A White Paper, Community Perspective" / R. D. Beger, W. Dunn, M. A. Schmidt [et al.] // Metabolomics. -2016. Vol. 12, № 9.-el49.

8. Nebert, D. W. Personalize medicine: temper expectations / D. W. Nebert, G. Zhang // Science. 2012. - Iss. 337 (6097). - e. 910.

9. New insights into genotype-phenotype correlation for individuals with different general nonspecific reactivity level (GNRL) of the organism mutations / A. Mulik, V. Novochadov, Yu. Shatyr, I. Ulesikova, A. Bondarev // J. Integrative Bioinformatics. - 2016. Vol. 13, №4. - e295.

10. Personalized vascular medicine: individualizing drug therapy/E. M. DeGoma, G. Rivera, S. M. Lilly [et al.] // Vascular Med. - 2011. - Vol. 16, № 5. - P. 391-404.

11. Precision medicine and molecular imaging: new targeted approaches toward cancer therapeutic and diagnosis / M. Ghasemi, I. Nabipour, A. Omrani [et al.] // Am. J. Nucl. Med. Mol. Imaging. - 2016. Vol. 6, № 6. - P. 310-327.

12. Scudellari, M. Genomics contest underscores challenges of personalized medicine / M. Scudellari // Nat. Med. - 2012. - Vol. 18, № 3. - P. 326.

13. Virtual screening SNP-polymorphisms of genes determining the high level of general nonspecific reactivity of organism / Y. A. Shatyr, A. M. Bondarev, V. V. Novochadov, A. B. Mulik // Eur. J. Mol. Biotech. -2015. - № 3. - P. 174-184.

14. Whitcomb, D. C. Going MAD: development of a «matrix academic division» to facilitate translating research to personalized medicine / D. C. Whitcomb // Acad Med. - 2011. - Vol. 86, № 11. - P. 1353-1359. 
М.В. Грунина, М.П. Лябин. Многомерная биология как основа персонализированной медицины

\section{Information about the Authors}

Maria V. Grunina, Senior Student, Department of Bioengineering and Bioinformatics, Volgograd State University, Prosp. Universitetskiy, 100, 400062 Volgograd, Russian Federation, biobio@volsu.ru.

Mikhail P. Liabin, Associate-professor, Department of Bioengineering and Bioinformatics, Volgograd State University, Prosp. Universitetskiy, 100, 400062 Volgograd, Russian Federation, biobio@volsu.ru.

\section{Информация об авторах}

Мария Викторовна Грунина, студентка кафедры биоинженерии и биоинформатики, Волгоградский государственный университет, проспект Университетский, 100, 400062 г. Волгоград, Российская Федерация, m.v.grunina@mail.ru.

Михаил Павлович Лябин, доцент кафедры биоинженерии и биоинформатики, Волгоградский государственный университет, проспект Университетский, 100, 400062 г. Волгоград, Российская Федерация, dollaps@mail.ru. 